\title{
Cómo era Rubén Darío
}

To veo ahora en mi mesa, lleno de luz: es el ejemplar de las obras poéticas completas de Darío. Su caparazón es una encuadernación negra, áspera, que presenta cierto aspecto utilitario y no está de acuerdo, seguramente, con su contenido. De repente pienso en Rubén, en la deleznable encarnación del pobre gran poeta. Me pregunto si, de un modo análogo, su fisionomía le apartaba del secreto sentido de su reino interior.

¿Cómo era Rubén de carne y hueso? Harto habrán visto ustedes los grabados y las fotografías de costumbre; también vieron (estoy segura de ello) el bosquejo que hizo Ochoa, ilustrador de tantos libros rubenianos, para la portada de su Autobiografía. Mas la luz que esparce el conjunto es tenue, tenue. Comprendo que una fotografía posee dos dimensiones y que carece de vitalidad. Por consiguiente, toda fotografía es un mero borrador, un simulacro, una penumbra.

Quizá contagiada de los sueños galantes del poeta, mi imaginación había urdido, confusamente, una noción de cómo era Darío: la visión ideal según el estudio de su obra; palpé (o creí palpar) la esencia de su corporalidad; quise descubrir las falsedades de mi concepto y abolirlas.

Formulé esta esperanza: abandonarme a los minúsculos informes difundidos al azar por los que le conocían. Tal pensamiento me sugirió un artículo en el que trazo, por medio de las palabras de sus contemporáneos, una especie de retrato de Rubén Darío. Se trata de una superposición de recuerdos.

Sin precisar la fecha de ellas, Darío mismo traza unas autoimpresiones que pueden servir como punto de partida a este ensayo. A eso de los catorce años, ya fué “... un muchacho con ojeras, con 
sueños y que se iba a confesar todos los sábados" (Autobiografía, p. 30). Y más tarde, cuando se presentó ante el gobernante de El Salvador, el doctor Rafael Zaldívar, Rubén era un "mozo flaco y de larga cabellera, pretérita indumentaria y exhaustos bolsillos" (Ibid., p. 41). Su mejor deseo, manifestado al presidente, el de tener una buena posición social, entraña un presagio: el afán aristocrático, el "yo no soy un poeta para muchedumbres", ulteriores, ya hallaron una calurosa acogida en la mente del inexperto adolescente.

E1 chileno Mariano Latorre comenta su aparición en Santiago, en la época en que se publicó su sorprendente libro $A z u l$...: "Darío pasea su bronceada figura de indio mal vestido por las calles de Santiago y por las redacciones de los diarios de la capital. Los elegantes caballeros santiaguinos lo ignoraron." (La literatura de Chile, p. 163). Otros historiarán la extrema elegancia de su vestir en los años posteriores.

Justo Sierra, Ministro de Instrucción Pública de México, intercala esta cordial relación, al prologar un libro de Darío: "Rubén no sólo es alto, intelectual y sensitivamente, sino físicamenț; es el suyo un cuerpo que a punto de ser atlético se detuvo negligente y perezoso y escondió una resistencia férrea a todos los surmenages, bajo una piel pálida patinada de bronce, $y$ una alma de artista afinada hasta el dolor, en un cráneo que revela su cúpula mística bajo la cabellera obscura cuidadosamente peinada, y detrás de unas pupilas color de tabaco, frías y silenciosas mientras no afocan uno cualquiera de los infinitos aspectos de lo bello, que entonces brilla en ellas una llama concentrada de pasión y de goce... grande, lento, siempre bien pergeñado y elegante..." (Peregrinaciones, pp. 10-11.)

José María Vargas Vila, cuya enemistad se convirtió en la más vehemente amistad hacia Darío, observa que "... todas las razas del mundo parecían haber puesto su sello en aquella faz, que era como una playa que hubiese recibido el beso de todas las olas del océano"; “... viéndolo así, pensé en Beethoven, con el cual tenía tan extraña semejanza física, y de cuyo genio melódico era hermano..." (Rubén Dario, pp. 22, 45-46.)

Roberto J. Payró conoció a Darío cuando ambos colaboraban en La Nación de Buenos Aires; mide su parquedad en el hablar, así: "Muchos lo creian taciturno, mal conversador. Generalmente se limitaba a monosílabos y frases cortas, mecha entre las charlas de los 
demás. Pero en la intimidad, lejos de los extraños, de los indiferentes, era un conversador amenísimo. En compañía de señoras hablaba más que nadie y era para ellas encantador. Su cara morena y algo tosca, se embellecía y en sus ojos brillaba una luz. iQuien lo viera y oyera en esas circunstancias, no lo olvidaría más!"' (Siluetas, p. 18).

Esta noticia trascendió de Lauxar: "Su rostro delataba una mestización ambigua, con rasgos mongólicos sobre una fisonomía vaga y borrosa de negro ... era muy sensible al gusto de vestir con atildamiento llamativo ... Tenía la tez mate, de color aceitunado, con barba y bigote ralos; el pelo, negro y crespo; la frente, combada, con las arcadas ciliares prominentes; los pómulos, gruesos; las mejillas, flácidas; ancho y hundido al medio, el mentón; la boca, espesa y grande; abultada, la nariz, y casi doble por la abertura excesiva de las fosas." (Rubén Dario y José Enrique Rodó, pp. 103-104).

Surgen a la conciencia de José María Salaverría "sus grandes y dulces ojos de mestizo", junto con estas impresiones: "El rostro grande y rapado de Rubén Darío se me presentó como la expresión de un espíritu que podría haber sido fuerte, y que no quiso serlo, un poco por desidia, o acaso porque no sintió la necesidad de ser fuerte... Observé en sus ojos una duplicidad de expresión. Había en aquella mirada tanto de amabilidad como de recelo, ese recelo vigilante que suele notarse en los hombres tímidos, inteligentes y que han viajado y vivido mucho." 1

Hay los que destacan su calidad de indio. Miguel de Unamuno habla del "... indio que temblaba con todo su ser;' como el follaje de un árbol azotado por el cierzo, ante el misterio" y "... aquella suprema flor espiritual de la indianidad." 2

Acompañan los recuerdos de R. Cansinos Assens estas líneas: “... y ante aquella alta y recia figura, encorvada por las melancolías del amor y del arte, ante aquel rostro moreno de indio bravo, contraído por un rictus de final desengaño, evocaba la parábola de una exótica selva virgen, devastada por el envenenado hálito europeo ... llevaba siempre la misma cara de sueño y de cansancio ... su efigie silenciosa esculpida en basalto... expresará bien la bruma de melancolía que en los últimos tiempos tornó negras las blancas alas de sus cisnes." ${ }^{3}$

Una plenitud de ironía yace en este comentario de J. Barrio y Bravo: "A buen seguro que las románticas muchachas que alguna 
vez, hojeando los libros de Rubén, hayan tropezado con aquella exquisita 'Sonatina' en que cantó el poeta la tristeza de una princesita soñadora, en todo habrán pensando, sin duda, menos en un bardo de cara abultada, de boca carnosa y rasgada y de nariz india." 4

Por diversas alusiones, tenemos la rudimentaria certidumbre de esta visión: Darío, el trasnochador desgreñado, combatiendo su hastío a través de un laberinto de brebajes. El peruano Felipe Sassone, con un candor resuelto, nos dice que "más de una vez, en el París galante o en el Buenos Aires cosmopolita, durante el alba que seguía a las noches de sensualidad, el pobre poeta, brumoso de spleen y luminoso de aurora, ebrio del amor de las peripatéticas y de wisky, de ajenjo y de champaña, abatíase en un diván profundo como su pena, y me hablaba de la muerte. -Felipe- deciame, mientras acariciaba las solapas de su smocking (sic) - revela a la posteridad que el poeta se muere y que el poeta vestía de seda." 5

Sassone evoca otra escena habitual: "Ya no le veré más a la puerta de las tabernas parisinas, esperar su tedio bajo la fronda del bulevard y soñar con Grecia mientras chupaba la miel que siempre llevara en un bote de latón en un bolsillo de su americana acaso porque todo un enjambre de áticas abejas habían reencarnado en el cuerpo rijoso y ultrasensible de aquel indio chorotega que tenía manos de marqués." 6

Y queda implacable la sumaria mención de “... este poeta del bello nombre y del feo rostro" " que suelta José Francés.

Diego Carbonell, el médico venezolano que atendió varias veces a Rubén Darío en París, retrocede en el tiempo, para revivir este recuerdo: "Era, sí, un hombre pulcro en el vestir; pero su aspecto exterior no inclinaba a la admiración; tenía facha de indio que no fuera puro indio; era de cuerpo pesado y el alcohol aumentaba las proporciones de su vientre." (Lo morboso en Rubén Dario, p. 89).

Entreteje lo siguiente Ramón Hurtado: "Su mirada era de laxitud y de tristeza" y "aquel hombre tenía unas manos de prelado, finas y pulcras. Gesticulaba con lentitud, armoniosamente, uniendo el pulgar y el índice..." (Ibid., p. 89).

Lo dice sin reticencias Rufino Blanco-Fombona: "Darío resulta protipo de este cautivante poeta de imaginación; prosaico, sin embargo, en la existencia, incoloro', aborregado, calculista, insignificante, nulo." (La lámpara de Aladino, p. 550). 
Ponderé las numerosas impresiones; ninguna coincidía con la que forjara de antemano. Siquiera por un momento imaginé ver a Darío, y la visión me pareció una equivocación atroz. Aclaro: tuve la sensación de encarar a un hombre desconocido.

Formular este retrato con recuerdos ajenos es puro trabajo maquinal; mas tiene un valor imprevisto. Cuando inventé, anteriormente, un retrato de Darío según su obra, apenas logré entrever su alma; prescindí por completo de su esencial humanidad. Al divisar al hombre en el fondo del poeta, aumentó mi comprensión de su poesía.

\section{Ruth L. Conzelman Simms, San Francisco, California.}

\section{$\mathrm{NOTHS}$}

1 Juan. González Olmedilla, La ofrenda de España a Rubén Dario. Madrid, 1916, p. 78.

2 Ibid., pp. 30-31.

3 Ibid., pp. 52-54.

4 Ibid., p. 173.

5 Ibid., p. 64.

6 Ibid., p. 68.

7 Ibid., p. 122. 
